\title{
Surgical Education and Academic Surgery: Quo Vadis?
}

\author{
Dhananjaya Sharma ${ }^{1}$ (D)
}

Received: 20 February 2022 / Accepted: 23 February 2022 /Published online: 27 February 2022

(c) Association of Surgeons of India 2022

For the last three and half decades, I have been passionately teaching the art and science of surgery. So, when the idea of this special issue on "Surgical education and Academic Surgery" popped up during a routine telephonic conversation with the Editor in Chief of "Indian Journal of Surgery," Professor Sandeep Kumar, I jumped at it eagerly. But more about this later.

Over this long period, both the discipline of Surgical Education and my approach as an avid teacher of it have undergone lot of changes. It is worth recounting some of them. When I was a student, the all-pervading doctrine in academia was, "shiksha daan supatra ko" (Sanskrit, Sukti/ Axiom), implying that "education should be imparted only to the deserving." However, when I transited from being a student to the responsible role of a teacher, the realization soon dawned that differentiating between deserving and undeserving students is an unenviable task, especially in the initial part of their careers, when those coming from modest backgrounds are still struggling to find their footing. Additionally, the conventional surgical teacher-trainee relationship is dauntingly hierarchical, thus leaving the student at a great disadvantage when seeking any help or mentorship. So I started assisting, "not" mentoring, everyone; and those who appreciated the quality of assistance elevated it to the level of "mentorship." Additionally, I made sure to reserve accepting the title of mentor only from those who had completed their training, as a conventionally authoritarian surgical training system can force cloying yesmanship.

I fell in love with and cultivated a teaching style based on the Socratic Method of Qs and As and the Japanese style of Shibumi. To paraphrase Professor Thomas Starzl: "trainees are like unguided missiles looking for aim and trajectory"; and we have to provide the much needed guidance. And in the evening of my career, it was very comforting to find that

Dhananjaya Sharma

dhanshar@gmail.com

1 Department of Surgery, Government NSCB Medical College, Jabalpur, MP 482 003, India my ideas were not dissimilar to those expressed by a famous Nobel Laureate in his "The Art of Scholarly Mentoring"! [1] When seeking a source of inspiration for finding simple innovative solutions, one did not have to look further than the strong historical influence of our own Sushruta (ancient Indian surgeon, $750 \mathrm{BC}$, widely known as the "Father of Surgery"). Learning and re-learning became the norm as newer techniques and technologies gradually got assimilated in the inventory of surgical armamentarium.

Normal surgical training, due to postponement of elective surgical services, was one of the "unsung" collateral victims of COVID pandemic. The word "unprecedented" is often paired with this ongoing pandemic; surgical training rose to the challenge and its response to address the problem has also been "unprecedented." It rapidly adapted by taking recourse to many e-learning resources like grand rounds, webinars, and multimedia operative atlases. These became available for trainees via videoconferencing, social media, and telemedicine. Many of these use immersive technologies like virtual reality (VR), augmented reality (AR), and mixed reality (MR) and provide Omni-Learning [2]. But, few of these advances have penetrated day to day surgical training, especially in the developing countries. This makes low-cost simulation a valuable and necessary adjunct to learning safe surgical skills when opportunities in the real clinical setting become inadequate [3]. Other ideas included global cooperation in medical/surgical education with greater involvement of medical teachers from the global South [4]. This has led to many of us teaching various "online" courses around the globe.

As surgical training embraced and reflected the diversity of newer educational technologies, the tech-savvy quality of the new generation smoothly adapted to these learning modalities. Obviously, such newer ideas will work best when they become part of our teaching/training system rather than as an isolated gap-filling application. This brings us to the next step of student-centered active learning technique which emphasizes self-direction and active inquiry, and the instructor's role is to foster critical reflection and facilitate the deeper understanding of new concepts and analytical 
aspects of decision making [5]. It is not difficult to envisage a utopian learning model in which the surgical trainee and the trainer are equal partners; the surgical trainee in the driving seat being co-helmed by his trainer. Such a partnership will go a long way in achieving the ideal growth of the trainee and making him a combination of surgical craftsman, a surgical intellectual, and a surgical researcher.

Finally, a common misconception is that good scientific research and good training only take place in large, highly research-intensive institutes; however, this is not true and many small and mid-sized institutions offer good academic as well as innovative research atmosphere and invaluable experiences for their trainees [6-8]. Another common theme running through realm of surgical education harps on the importance of evidence-based teaching rather than eminence-based teaching. It is akin to the age old discourse on knowledge vs. wisdom. The rightful place of evidencebased medicine is assured; however, evaluating evidence (knowledge) and knowing how to apply it can only be done by the experience of eminence (wisdom). This becomes even more crucial when the time to evaluate newly accruing evidence is not available, as seen in the pandemic [9]. The erstwhile "Town Vs. Gown" conflict between the private and teaching hospitals is fortunately a thing of past as the rapidly expanding model (DNBs, Fellowships) of involving private hospitals in surgical training is using their previously untapped vast potential and wisdom of surgeons working in them. I have yet to meet a surgeon who is not a compulsive teacher-it is inbuilt in their DNA — and the intrepid trainee, roaming as a surgical nomad, can reap the harvest, no matter where he/she goes.

So, coming back to this special issue which has been a labor of love since last 1 year! Almost all the colleagues accepted my invitation to contribute (first one landing in my inbox within $72 \mathrm{~h}$ of my invitation email!), and most of them did eventually contribute, albeit forcing us to stretch the deadline a "bit." My friends who have undertaken similar academic exercises tell me that contribution from $>90 \%$ invitees, and a delay of only $\sim 4$ months, is like a proverbial windfall. I am truly blessed to have such friends and colleagues around the Globe who responded positively to my cri de Coeur. My heartfelt thanks to them. The icing on the cake is the foreword written by Nobel Laureate Professor Jean-Marie Lehn, containing priceless pearls of wisdom. He has been a source of inspiration to so many of us.

"Surgical education" and "academic surgery" are not two different fields but complement each other and contribute to enriching surgery as a science and an art. It is difficult to put these two disciplines in any type of strait-jacket, so I deliberately avoided suggesting any particular format or definition; and the contributing authors were free to unravel various nuances of these two wonderful disciplines. They expressed their thoughts in individual writing styles, thus making this issue a bouquet of diversity from across the globe. To begin with, we have traditional articles on "academic surgery" and "mentorship." Several Surgical Colleges and National Surgical/ Speciality Associations from Australia, Bhutan, Europe, Glasgow, Ireland, Japan, Philippines, Singapore, Thailand, and the USA have shared the philosophy of their surgical education/training. Development of new surgical specialities and subspecialties has received attention as have the challenges of women trainees, difficulties faced by trainees during the COVID-19 pandemic, including the dreaded "burnout." UGs and PGs from India and the UK have shared their thoughts on surgical education/curriculum, while newer ideas/immersive technologies in education and training also find their place, including training of effective trainers, simulation training, and surgical skill assessment and incorporation of EBM in training. A remarkable feature is the excellence of traditionally "non-teaching" private hospitals in current surgical training with various governmentapproved programs. The new discipline of "Global" Surgery and its training availability has also found its pride of place as does an article comparing surgical training/curricula in India, the UK, and the USA.

And finally it is my pleasant duty to thank all those whose help was invaluable. Our venerable Editor-in-Chief Professor Sandeep Kumar gets the pride of place in this list; I just marvel at his ability to respond to my multiple (too many!) phone calls with his typical helpful attitude, unfailing courtesy, good humor, and enviable lakhnavi andaz. I got to learn so many things from him. My comrades in arms, Professors Pawan Agarwal and Vikesh Agrawal, were always by my side-supporting and helping me throughout this very pleasant endeavour.

So welcome to this special issue; I hope all of you will enjoy the eclectic range of articles.

\section{Declarations}

Conflict of Interest The author declares no competing interests.

\section{References}

1. Lefkowitz R (2021) The art of scholarly mentoring. https://www. insidehighered.com/advice/2021/01/26/nobel-laureate-shares-10rules-being-effective-mentor-young-research-scholars. Accessed 29 Jan 2021

2. Pears M, Yiasemidou M, Ismail MA, Veneziano D, Biyani CS (2020) Role of immersive technologies in healthcare education during the COVID-19 epidemic. Scott Med J 65(4):112-119. https://doi.org/10.1177/0036933020956317

3. Sharma D, Agrawal V, Bajaj J, Agarwal P (2020) Low-cost simulation systems for surgical training: A narrative review. Journal of 
Surgical Simulation 7:33-52. https://doi.org/10.1102/2051-7726. 2020.0005

4. Buitendijk SE, Ward H, Shimshon GJ, Sam AH, Sharma D, Harris M (2020) COVID19: an opportunity to rethink global cooperation in higher education and research. BMJ Glob Health 5(7):e002790. https://doi.org/10.1136/bmjgh-2020-002790

5. Lewis CE (2020) The flipped classroom: abandon the sage on the stage, and embrace the guide on the side. https://www.facs.org/ education/division-of-education/publications/rise/articles/flipped. Accessed 19 July 2020

6. Ling DS, Gerecke KM (2021) Stop undervaluing smaller institutions. Nature. https://doi.org/10.1038/d41586-021-02538-y

7. Sharma D, Agrawal V, Agarwal P (2021) Roadmap for clinical research in resource-constrained settings. Trop D 51(1):4-5. https://doi.org/10.1177/0049475520974844a
8. Sharma D, Agarwal P, Agrawal V (2022) Surgical Innovation in LMICs - the perspective from India. The Surgeon 20(1):16-40. https://doi.org/10.1016/j.surge.2021.11.002

9. Sharma D, Kumar S (2020) Editorial: What Makes A Surgical Teacher Great? Ind J Surg 82:999-1004. https://doi.org/10.1007/ s12262-020-02646-5

Publisher's Note Springer Nature remains neutral with regard to jurisdictional claims in published maps and institutional affiliations.

$20^{\text {th }}$ February 2022 